\title{
Transitions in Gambling Participation during Late Adolescence and Young Adulthood
}

\author{
Bethany C. Bray, PhD ${ }^{1}$, Grace P. Lee, $\mathrm{PhD}^{2}$, Weiwei Liu, $\mathrm{PhD}^{2}$, Carla L. Storr, $\mathrm{ScD}^{2,3}$, \\ Nicholas S. lalongo, $\mathbf{P h D}^{2}$, and Silvia S. Martins, $\mathbf{M D}, \mathbf{P h D}^{2,4}$ \\ ${ }^{1}$ The Methodology Center, The Pennsylvania State University \\ 2Department of Mental Health, Johns Hopkins Bloomberg School of Public Health \\ ${ }^{3}$ Department of Family and Community Health, University of Maryland School of Nursing \\ ${ }^{4}$ Department of Epidemiology, Columbia University
}

\section{Abstract}

Purpose-The purpose of this study was to examine transitions in gambling participation from late adolescence into emerging adulthood, and to identify factors (i.e., gender, race, intervention status, lunch status, conduct disorder, parental monitoring, neighborhood environment, and substance use) that might influence these transitions.

Methods-Markov modeling was used to describe movement between past-year gambling states (i.e., non-gambling and gambling) over five years. Annual data on past-year gambling behavior and substance use were collected from 515 young men and women starting at age 17 .

Results-Past-year gambling declined from 51\% prevalence at age 17 to $21 \%$ prevalence at age 22. Participants who reported no past-year gambling at a particular annual assessment had more than an $80 \%$ probability of also reporting no past-year gambling at the following assessment. Men were 1.07-2.82 times more likely than women to transition from past-year non-gambling to gambling year-to-year, and women were 1.27-5.26 times more likely than men to transition from past-year gambling to non-gambling year-to-year. In addition, gender and past-year tobacco use interacted such that men who used tobacco were most likely (and men who did not use tobacco least likely) to gamble at baseline.

Conclusions-Transition rates between gambling states appear to be relatively stable over time from late adolescence into emerging adulthood; however, men and those who engage in substance use may be at increased risk for gambling participation.

Implications and Contribution-The current study provides important information about the naturalistic transitions in gambling behavior during late adolescence and emerging adulthood

(C) 2014 Society for Adolescent Medicine. Published by Elsevier Inc. All rights reserved.

Correspondence concerning this article should be addressed to Silvia S. Martins, Department of Epidemiology, Columbia University, 722 West $168^{\text {th }}$ Street, Room 509, New York, NY 10032.ssm2183@ columbia.edu.

Publisher's Disclaimer: This is a PDF file of an unedited manuscript that has been accepted for publication. As a service to our customers we are providing this early version of the manuscript. The manuscript will undergo copyediting, typesetting, and review of the resulting proof before it is published in its final citable form. Please note that during the production process errors may be discovered which could affect the content, and all legal disclaimers that apply to the journal pertain. 
among an urban, mainly ethnic minority population. The finding that approximately half of pastyear gamblers do not gamble during the following year suggests that gambling follows a variable developmental course.

\section{Keywords}

gambling; tobacco; alcohol; marijuana; drugs; adolescence; emerging adulthood; latent transition analysis; Markov models

\section{Introduction}

Gambling is being recognized as an important public health concern ${ }^{1}$ as the availability of legalized opportunities continues to expand in the United States. ${ }^{2}$ Much of the work on adolescent and adult gambling has been conducted with cross-sectional studies, limiting the ability to draw conclusions about normative gambling development. Studies have used different methodologies to provide insight into longitudinal changes in gambling behavior and serve as the foundation for the current study. Vitaro et al. ${ }^{3}$ examined longitudinal trajectories of gambling among male French Canadian youth aged 11-16. Three trajectories indicated low gambling, chronic high gambling, and late-onset gambling. Another study by Betancourt et al. ${ }^{4}$ used similar methods and identified two trajectories of gambling behavior (i.e., early gambling and later gambling) among adolescents aged 10-15. Gender, coping mechanism, impulsivity, and substance use all were associated with trajectory group membership. The methods used by Vitaro et al. ${ }^{3}$ and Betancourt et al. ${ }^{4}$ provide a flexible approach to identify clusters of individuals' continuous, developmental trajectories within the population and descriptions of characteristics of individuals within the clusters. ${ }^{5}$

Evidence suggests that gambling behavior over time does not follow a smooth, continuous curve but has considerable intra-individual variability with discontinuous change between discrete states over time. Among college students assessed annually for four years, Goudriaan et al. ${ }^{6}$ created four gambling classes at each assessment from data on past-year gambling activities. One class consisted of students who did not gamble or gambled very sporadically (i.e., low gambling); the three other classes were based on primary gambling activity (i.e., card gambling, casino/slot gambling, and extensive gambling). There was considerable mobility between the low gambling and any of the other three gambling classes year-to-year.

Gender, race/ethnicity, and substance use are three of the most important correlates of gambling for both adolescents and adults. ${ }^{7}$ Research has consistently shown that gambling and problem gambling are more prevalent among males than females. ${ }^{8}$ Females also tend to initiate gambling later in life (i.e., in adulthood) compared to males and have a faster progression to problem gambling than males. ${ }^{9-12}$ Research also shows that ethnic minorities, particularly African Americans, have higher prevalence of gambling and problem gambling than Caucasians. ${ }^{13}$

Parental monitoring serves to limit deviant behavior by bolstering parents' ability to manage their children's behavior ${ }^{14-17}$. High parental monitoring during adolescence can serve as a protective factor associated with non-gambling, delayed gambling initiation, and transitions 
from gambling back to non-gambling. Cross-sectional studies have found that high parental monitoring decreased the odds of gambling among youth ${ }^{18,19}$, but one longitudinal study found no such association ${ }^{20}$. Lee et al. ${ }^{15}$ showed that higher parental monitoring during early adolescence (ages 11-14) was associated with less problem gambling between ages 16-22. It is important to consider the effects of protective factors like parental monitoring in addition to those of risk factors like gender and substance use when examining transitions in gambling behavior.

An important gap in the current gambling literature deals with potentially discrete transitions in gambling behavior over time, particularly among urban, predominantly minority youth. The purpose of this study is to (1) examine naturalistic transitions in past-year gambling participation from adolescence (age 17) into emerging adulthood (age 22), and (2) examine how key demographic characteristics and behaviors, as well as parental monitoring, may influence these transitions among a longitudinal sample of urban, primarily African American, low socio-economic status (SES) youth. Transitions among states reflecting gambling severity (i.e., non-gambling, social gambling, and at-risk or problem gambling) were considered, but could not be examined due to low rates of at-risk or problem gambling in this community-based sample.

\section{Method}

\section{Participants}

Data for the current study were from the Johns Hopkins University Center for Prevention and Early Intervention Second Generation Intervention Trial (JHU PIRC). ${ }^{21}$ The JHU PIRC is a longitudinal prospective study that recruited urban first graders (age 7) in Baltimore, MD in the fall of 1993. Detailed information about the trial design is available elsewhere. ${ }^{21}$ Using a randomized block design with schools as the blocking factor, classrooms were divided into two intervention groups and a control group. One intervention was classroom based and the other involved parents; the control group received the usual school curriculum. Both interventions were designed to impact long-term antisocial behavior, substance use, anxiety, and depression by increasing achievement and reducing aggressive behavior. The intervention component of the JHU PIRC lasted one year, but students were followed up annually.

A total of 678 students participated in the original study (46.6\% female; $86.3 \%$ African American). The sample for the current study consisted of 515 individuals ( $45.0 \%$ female; 87.8\% African American; $76.0 \%$ of the original sample) who provided data on gambling participation for at least one wave of data collection during the course of the study, and who provided data on all substance use predictors of interest. Distal outcome measures on pastyear gambling were collected from participants annually from 2004 (age 17; i.e., reporting on behavior since age 16) to 2009 (age 22; i.e., reporting on behavior since age 21), except in 2005 (when gambling data were not collected due to lack of funding). Demographic characteristics of the participants and prevalence of missing data are summarized in Table 1. Of the 515 participants analyzed, 357 (69.3\%) provided data on gambling behavior at all five waves, $85(16.5 \%)$ at four waves, $39(7.6 \%)$ at three waves, $22(4.3 \%)$ at two waves, 
and $12(2.3 \%)$ at one wave. Excluded students did not differ significantly from participants analyzed here on gender, birth year, race, free lunch status, or intervention status ( $p>.05)$.

\section{Measures}

Gambling-Past-year gambling was the primary outcome of interest. Two gambling instruments assessed gambling involvement. The South Oaks Gambling Screen-Revised for Adolescents $^{22}$ (SOGS-RA) assessed annual gambling frequency (i.e., not at all, less than once a week, at least once a week), type of gambling activities (e.g., lottery), and gambling problems (e.g., hiding evidence of gambling). The SOGS-RA uses items whose wordings and response options have been adapted from the South Oaks Gambling Screen ${ }^{23}$ (SOGS) to reflect adolescent gambling behavior at an age appropriate reading level. The SOGS-RA was administered at ages 17, 19 and 20 (in years 2004, 2006 and 2007), and had Cronbach's alphas ranging from .61-.72. The SOGS assessed annual gambling frequency, activities, and problems at ages 21 and 22 (in years 2008 and 2009), and had Cronbach's alphas ranging from .60-.70. Participants were categorized at each wave as past-year non-gamblers or pastyear gamblers according to their responses to Question 1 of the SOGS-RA/SOGS, which asks about 13 different types of gambling activities. Prevalence of past-year gambling during the course of the study and missing data are summarized in Table 2.

Gambling problems were assessed using twelve dichotomous (i.e., yes/no) items from the SOGS-RA/SOGS. The number of problems reported by each participant was summed (range $=0-12$ ). Based on Winters et al.' ${ }^{22}$ (for the SOGS-RA) and Lesieur and Blume's ${ }^{23}$ (for the SOGS) proposed criteria, problem gambling categories were created: (1) nongamblers reported neither gambling nor any gambling problems; (2) social gamblers reported up to 1 problem; (3) at-risk problem gamblers reported 2-3 problems; and (4) problem gamblers reported 4 or more problems. However, due to the small number of at-risk and problem gamblers we were unable to run meaningful analyses examining transitions among these categories. This was not possible even when combining at-risk and problem gamblers (often done because they share similar characteristics ${ }^{24,25}$ ); see Table 2 for prevalence of problem gambling.

Demographics-School records provided information on gender, birth year, race, lunch status (i.e., free/reduced lunches vs. paid lunches; a proxy for SES), and intervention status.

Conduct disorder-The Diagnostic Interview Schedule for Children-IV ${ }^{26}$ (DISC-IV) Conduct Disorder module was used to assess conduct disorder at age 17.

Parental Monitoring-The Parental Monitoring subscale of the Structured Interview of Parent Management Skills and Practices-Youth (SIPMSP-Youth) ${ }^{27}$ was used to assess parental monitoring at age 17. The SIPMSP-Youth consists of 7 items (e.g., how often is your parent at home within one hour after you get home from school) using a 5-point Likert scale $(1=$ never, $5=$ all of the time); higher average scores across items indicate higher overall monitoring levels (alpha $=.87)$.

Neighborhood environment-Neighborhood environment as measured at age 17 was assessed using a 10-item scale based on an instrument originally developed by Elliott et al. ${ }^{28}$ 
The items assessed safety (e.g., plenty of safe places to walk or spend time outdoors), neighborhood violence (e.g., every few weeks adults and kids get beaten up or mugged), law abidance (e.g., most adults respect the law), and drug use (e.g., people with money are the drug dealers). Participants rated each item using a 4-point Likert scale ( $1=$ not at all true, 4 $=$ very true), with higher scores indicating greater degree of neighborhood disadvantage $($ alpha $=.85)$.

Substance use-Past-year use of tobacco, alcohol, marijuana, and other drugs at ages $17-22$ were assessed via self-report with questions adapted from Monitoring the Future. ${ }^{29}$ Other drug use included use of cocaine, crack, heroin, ecstasy, hallucinogens, and inhalants. Participants were identified as either not having used a substance or having used a substance in the past year. Prevalence of past-year tobacco, alcohol, marijuana, and other drugs are summarized in Table 2.

\section{Analysis Plan}

A Markov modeling-based approach was used to examine longitudinal change in gambling participation within individuals. This approach accommodates frequent discrete transitions between qualitatively different stages of behavior, and does not require modeling behavior as a smooth function of time. It provides a way to describe and predict movement between states of participation and non-participation in gambling. Markov models that address change over time in unobserved latent variables can be fit using latent transition analysis. ${ }^{30}$ Gambling and non-gambling were the two stages of interest, and they were measured using a single indicator at each time assuming no measurement error. This method provides estimates of stage membership at baseline, change between stage membership from time $t$ to time $t+1$, and effects of predictors on both stage membership and changes over time in stage membership.

Effects of predictors are estimated via logistic regression in the context of the Markov model. That is, binary logistic regression is used to provide estimates of the effects of a oneunit increase in a predictor on the log odds of past-year gambling compared to non-gambling at baseline (age 17). It also provides estimates of the effects of a one-unit increase in a predictor on the log odds of transitioning to, for example, gambling relative to staying nongambling between two assessment waves. Significance of effects is determined via likelihood ratio tests.

First, to examine naturalistic transitions in gambling participation, a baseline model was fit to estimate the prevalence of past-year gambling stages at each assessment wave, and transition rates between stages for adjacent waves. Second, to examine how key risk and protective factors may influence transitions in gambling participation, gender, race, intervention status, lunch status, conduct disorder, parental monitoring, neighborhood environment, and each type of substance use were individually added as covariates to the baseline model to determine whether they predict gambling stage membership and transitions in stage membership over time. Third, multiple types of substance use (past-year tobacco, alcohol, and marijuana use) were added as covariates to the baseline model simultaneously to determine whether certain substances played more important roles than 
others. Fourth, past-year tobacco and alcohol use were added as time-varying covariates to the baseline model simultaneously. Fifth, interactions between gender and substance use were considered.

The outlined analysis plan uses the same approach as that used to model transitions into and out of light/intermittent smoking from adolescence to emerging adulthood. ${ }^{31}$ All models were estimated using PROC LTA ${ }^{32}$ and replicated using Mplus. ${ }^{33}$ Both PROC LTA and Mplus use a full information maximum likelihood-based estimation procedure, which handles missing data on the observed indicators using the expectation-maximization algorithm; this algorithm assumes data are missing at random.

\section{Results}

\section{Baseline Model (Age 17)}

Table 3 shows the prevalence of past-year gambling stage membership at each wave from age 17-22 (2004-2009), and the transition rates between stages for adjacent waves. The proportion of past-year gamblers declined over time, from 51\% at age 17 to $21 \%$ at age 22 .

The transition rates are the proportions of individuals in the gambling stages at time $t+1$ conditional on gambling stage membership at time $t$. In general, non-gamblers showed high stability from year-to-year, meaning that participants who reported no past-year gambling at time $t$ had a high probability of reporting no past-year gambling at time $t+1$. For example, from Table 3, 87\% of participants who reported no past-year gambling at age 17 also reported no past-year gambling at age 19; the rates remained relatively consistent, ranging from $82 \%$ to $88 \%$. Conversely, the rates of transitioning from non-gambling to gambling over the course of a year ranged from $12 \%$ to $18 \%$.

Although transition rates describe the annual rate of change, they do not provide information about the proportions of participants who remained non-gamblers or gamblers over the course of the study. Of those participants who provided data at all five waves $(n=357)$, $35.0 \%$ reported non-gambling throughout the course of the study and 3.6\% reported gambling throughout the course of the study. In comparison, of the full sample $(n=515)$, $34.8 \%$ reported non-gambling throughout the course of the study when data were provided and $7.4 \%$ reported gambling throughout the course of the study when data were provided.

\section{Effects of Predictors}

Predictors were added as covariates individually to the Markov baseline model to determine whether they were related to baseline (age 17) gambling stage membership and longitudinal transitions in stage membership. As expected, gender was significantly related both to baseline membership $\left(\chi^{2}=29.6, d f=1, p<.001\right)$ and to longitudinal transitions $\left(\chi^{2}=38.5, d f=8\right.$, $p<.001)$. The effects of gender are represented by odds ratios and are summarized in Table

4. At baseline, men were 2.66 times more likely than women to be past-year gamblers. Men were also always more likely than women to transition from non-gambling to gambling, but the magnitude of this effect varied across assessments. For example, the largest gender effect on transitioning to gambling occurred between age 20 and age 21, when men were 2.82 times more likely than women to transition from non-gambling to gambling. Similarly, 
women were always more likely than men to transition from gambling to non-gambling, with varying magnitudes across assessments. The largest gender effect on transitioning to non-gambling occurred between age 19 and age 20, when women were (1/.19)=5.26 times more likely than men to transition from gambling to non-gambling.

Intervention status, lunch status, conduct disorder, parental monitoring, neighborhood environment, and past-year other drug use were not significant predictors of baseline gambling stage membership or longitudinal transitions in stage membership. In contrast, past-year use of tobacco, alcohol, and marijuana at baseline (age 17) were significant predictors of baseline membership, even after controlling for gender, but not of longitudinal transitions. Table 5 shows the effects of tobacco, alcohol, and marijuana use on baseline gambling stage membership, controlling for gender, when the substances were considered individually and simultaneously. When tobacco, alcohol, and marijuana use were considered simultaneously, marijuana use no longer significantly predicted baseline membership; when tobacco and alcohol use or tobacco and marijuana use were considered simultaneously, both significantly predicted baseline membership. Controlling for gender, individuals who had used tobacco in the past year were 1.59-2.06 times more likely than non-users to have gambled in the past year. Similarly, controlling for gender, past-year alcohol users were 1.60-2.00 times more likely than non-users to have gambled in the past year.

In addition, gender and past-year tobacco use (but not gender and past-year alcohol use) interacted significantly in their prediction of baseline (age 17) gambling stage membership (interaction odds ratio $=2.64, p=.03$ ). That is, at baseline, men and women who used alcohol in the past year were approximately equally likely also to gamble in the past year, but men who used tobacco in the past year were most likely also to gamble in the past year (58\%) and men who did not use tobacco in the past year were least likely also to gamble in the past year (30\%). Table 5 summarizes the prevalence of past-year gambling stages for combinations of gender and past-year tobacco use.

Finally, time-varying past-year use of tobacco and alcohol were significant predictors of longitudinal transitions in gambling stage membership, but this effect became nonsignificant when controlling for gender. There also was no significant interaction between gender and time-varying past-year tobacco use on longitudinal transitions in gambling stage membership.

\section{Discussion}

The current study examined transitions in gambling behavior, and effects of key demographic and behavioral factors on these transitions, among a longitudinal sample of urban, primarily African-American youth. Annual assessments from age 17 (2004) to age 22 (2009), with the exception of age 18 (2005), when gambling data were not collected, were included in the analysis. The prevalence of past-year gambling declined from $51 \%$ at age 17 to $21 \%$ at age 22 . Non-gamblers showed high stability year-to-year; participants who reported no past-year gambling at a particular assessment wave had more than an $80 \%$ chance of reporting no gambling at the subsequent wave. In comparison, past-year gamblers showed considerably less stability year-to-year; participants who reported past-year 
gambling at a particular assessment wave had a $36-51 \%$ chance of reporting gambling at the subsequent wave.

These results somewhat support those of Goudriaan et al. ${ }^{6}$ that found stability was highest among those with no/low-level gambling. In the current study, $87 \%$ of participants who reported no past-year gambling at baseline also reported no past-year gambling at last follow-up. However, the results presented here show lower rates of past-year gambling stability than Goudriaan et al. ${ }^{6}$

The relatively high rate of longitudinal transitions from gambling to non-gambling supports the conclusion by Slutske et al. ${ }^{34}$ that gambling development does not necessarily follow a smooth curve but that there is considerable movement between states, and considerable intra-individual variability over time. Further, the high rate of naturalistic transitions from past-year gambling to non-gambling (e.g., 49-64\% of gamblers reported non-gambling at the subsequent assessment) also lends tentative support to work on the concept of "natural recovery," referring specifically to problem gamblers in that most with a history of problem gambling "recover" from the disorder with no formal treatment. ${ }^{35}$ The current findings could suggest that the course of problem gambling follows that of more normative gambling behavior. This reinforces the importance of examining gambling behavior over time, using appropriate statistical approaches for discrete or continuous data depending on the specific context, to better distinguish those who are at risk for problem gambling.

Regarding the effects of predictors on the transitions between past-year gambling stages, the results of the current study support the consistent finding that gender is one of the strongest correlates of gambling behavior. ${ }^{4,}, 12$ Not only were men 2.66 times more likely than women to be past-year gamblers at baseline, they were also 1.07-2.86 times more likely to transition from non-gambling to gambling year-to-year. Conversely, women were 1.27-5.26 times more likely to transition from gambling to non-gambling year-to-year. The current findings could be affected by the generally low gambling prevalence among women during late adolescence and emerging adulthood as women tend to initiate gambling later in life. ${ }^{36}$ Had the current study period been later in life, women could have been more similar to men in their likelihood of transitioning from non-gambling to gambling or remaining gamblers from year-to-year. In addition, the large odds ratios for women transitioning into nongambling in young adulthood suggest that gambling at this age is considered more normative and acceptable among men than women. Our findings parallel findings from Winters et al. ${ }^{37}$ that assessed gambling behaviors in young adults over three waves and described that men were more likely to gamble than women at all waves.

Past-year tobacco, alcohol, and marijuana use were all positively associated with past-year gambling at baseline. Such associations reflect assertions made by Problem Behavior Theory, ${ }^{38}$ positing that youth often engage in multiple problem behaviors at once. In addition, gender and past-year tobacco use interacted significantly in their prediction of baseline (age 17) gambling stage membership: men who used tobacco in the past year were most likely also to gamble in the past year. This suggests that gambling during the transition to adulthood is more normative among male adolescent who are tobacco users than among those who do not smoke. 
The current study has several strengths and limitations. A major strength is the sample, which was selected from an epidemiologically defined population representative of African American students in schools in urban neighborhoods. This provides an opportunity to examine an under-studied behavior (i.e., gambling) in an under-studied population. A second strength is the availability of longitudinal data on gambling and substance use. However, the current study also has several limitations. One is that questions about gambling behavior were not asked at age 18 as they had been omitted from the questionnaires. Secondly, data on gambling and substance use were based on self-reports, which could be subject to recall and social desirability bias. Third, data on several potential protective factors were not collected.

In conclusion, this study provides important information about naturalistic transitions in gambling behavior during late adolescence and emerging adulthood among an urban, predominantly African American, population. It is important to note that a third of those who gambled in the past year at age 17 also gambled in the past year at age 22. Consistent, long-term gamblers may need to be targeted by prevention programs.

\section{Acknowledgments}

This study was funded by a research grant from the National Institute of Child and Human Development, National Institutes of Health (NICHD-NIH, RO1HD060072-P.I. Dr. Martins). The JHU PIRC Second Generation Intervention Trial is funded by National Institute on Drug Abuse grant RO1DA11796 (P.I. Dr. Ialongo). We thank Scott Hubbard for data management and Julian Santaella for manuscript formatting.

\section{References}

1. Korn D, Gibbins R, Azmier J. Framing public policy towards a public health paradigm for gambling. J Gambl Stud. 2003; 19:235-256. [PubMed: 12766471]

2. Korn DA, Shaffer HJ. Gambling and the Health of the Public: Adopting a Public Health Perspective. J Gambl Stud. 1999; 15:289-365. [PubMed: 12766466]

3. Vitaro F, Wanner B, Ladouceur R, et al. Trajectories of gambling during adolescence. J Gambl Stud. 2004; 20:47-69. [PubMed: 14973397]

4. Betancourt LM, Brodsky NL, Brown CA, et al. Is executive cognitive function associated with youth gambling? J Gambl Stud. 2012; 28:225-238. [PubMed: 21698342]

5. Nagin D. Analyzing developmental trajectories: A semi-parametric, group-based approach. Psychological Methods. 1999; 4:139-177.

6. Goudriaan AE, Slutske WS, Krull JL, et al. Longitudinal patterns of gambling activities and associated risk factors in college students. Addiction. 2009; 104:1219-1232. [PubMed: 19438422]

7. Barnes GM, Welte JW, Hoffman JH, et al. Gambling, alcohol, and other substance use among youth in the United States. J Stud Alcohol and Drugs. 2009; 70:134-142. [PubMed: 19118402]

8. Martins SS, Storr CL, Ialongo NS, et al. Gender differences in mental health characteristics and gambling among african-american adolescent gamblers. Am J Addict. 2008; 17:126-134. [PubMed: 18393056]

9. Desai RA, Maciejewski PK, Pantalon MV, et al. Gender differences in adolescent gambling. Ann Clin Psychiatry. 2004; 17:249-258. [PubMed: 16402759]

10. Grant JE, Odlaug BL, Mooney ME. Telescoping phenomenon in pathological gambling: association with gender and comorbidities. J Nerv Ment Dis. 2012; 200:996-998. [PubMed: 23124186]

11. Ibáñez A, Blanco C, Moreryra P, et al. Gender differences in pathological gambling. J Clin Psychiatry. 2003; 64:295-301. [PubMed: 12716271] 
12. Tavares H, Martins SS, Lobo DS, et al. Factors at play in faster progression for female pathological gamblers: An exploratory analysis. J Clin Psychiatry. 2003; 64:433-438. [PubMed: 12716246]

13. Welte JW, Barnes GM, Tidwell MC, et al. The prevalence of problem gambling among U.S. adolescents and young adults: results from a national survey. J Gambl Stud. 2008; 24:119-133. [PubMed: 18097737]

14. Dishion TJ, McMahon RJ. Parental monitoring and the prevention of child and adolescent problem behavior: A conceptual and empirical formulation. Clin Child Fam Psychol Rev. 1998; 1:61-75. [PubMed: 11324078]

15. Lee GP, Stuart EA, Ialongo NS, et al. Parental monitoring trajectories and gambling among a longitudinal cohort of urban youth. Addiction. in press.

16. Pettit GS, Bates JE, Dodge KA, et al. The impact of after-school peer contact on early adolescent externalizing problems is moderated by parental monitoring, perceived neighborhood safety, and prior adjustment. Child Dev. 1999; 70:768-778. [PubMed: 10368921]

17. Stattin H, Kerr M. Parental monitoring: A reinterpretation. Child Dev. 2000; 71:1072-1085. [PubMed: 11016567]

18. Vachon J, Vitaro F, Wanner B, et al. Adolescent gambling: relationships with parent gambling and parenting practices. Psychol Addict Behav. 2004; 18:398-401. [PubMed: 15631615]

19. Vitaro F, Brendgen M, Ladouceur R, et al. Gambling, delinquency, and drug use during adolescence: Mutual influences and common risk factors. J Gambl Stud. 2001; 17:171-190. [PubMed: 11761603]

20. Barnes GM, Welte JW, Hoffman JH, et al. Shared predictors of youthful gambling, substance use, and delinquency. Psychol Addict Behav. 2005; 19:165-174. [PubMed: 16011387]

21. Ialongo N, Poduska J, Werthamer L, et al. The distal impact of two first-grade preventive interventions on conduct problems and disorder in early adolescence. J Emotional Behavioral Disord. 2001; 9:146-160.

22. Winters KC, Stinchfield RD, Fulkerson J. Toward the development of an adolescent gambling problem severity scale. J Gambl Stud. 1993; 9:63-84.

23. Lesieur HR, Blume SB. The South Oaks Gambling Screen (SOGS): A new instrument for the identification of pathological gamblers. Am J Psychiatry. 1987; 144:1184-1188. [PubMed: 3631315]

24. Hardoon KK, Derevensky JL. Child and adolescent gambling behavior: Current knowledge. Clin Child Psychol Psychiatry. 2002; 7:263-281.

25. Stucki S, Rihs-Middel M. Prevalence of adult problem and pathological gambling between 2000 and 2005: An update. J Gambl Stud. 2008; 23:245-257. [PubMed: 17216582]

26. Shaffer D, Fisher P, Lucas CP, et al. NIMH Diagnostic Interview Schedule for Children Version IV (NIMH DISC-IV): description, differences from previous versions, and reliability of some common diagnoses. J Am Acad Child Adolesc Psychiatry. 2000; 39:28-38. [PubMed: 10638065]

27. Capaldi, D.; Patterson, GR. Psychopathy and antisocial personality: a developmental perspective. New York, NY: Springer; 1994. Interrelated influences of contextual factors on antisocial behavior in childhood and adolescence for males; p. 165-198.

28. Elliott, DS.; Ageton, SS.; Huizinga, D. Explaining delinquency and drug use. Beverly Hills, CA: Sage; 1985.

29. Johnston, LD.; O’Malley, PM.; Bachman, JG. National survey results on drug use from the Monitoring the Future study, 1975-1994. Ann Arbor, MI: The University of Michigan; 2005.

30. Collins, LM.; Lanza, ST. Latent class and latent transition analysis: With applications in the social, behavioral, and health sciences. Wiley; 2010.

31. White HR, Bray BC, Fleming CB, et al. Transitions into and out of light and intermittent smoking during emerging adulthood. Nic Tob Res. 2009; 11:211-219.

32. Lanza, ST.; Dziak, JJ.; Huang, L., et al. PROC LCA \& PROC LTA users' guide. 1.3.0. University Park: The Methodology Center, Penn State; [2013]

33. Muthen, LK.; Muthen, BO. Mplus users' guide. Los Angeles, CA: Muthen \& Muthen; 1998-2012.

34. Slutske WS, Jackson KM, Sher KJ. The natural history of problem gambling from age 18 to 29 . J Abnorm Psychol. 2003; 112:263-274. [PubMed: 12784836] 
35. LaPlante D, Nelson S, LaBrie R, et al. Stability and progression of disordered gambling: Lessons from longitudinal studies. Can J Psychiatry. 2008; 53:52-60. [PubMed: 18286872]

36. Nelson S, LaPlante D, LaBrie R, et al. The proxy effect: Gender and gambling problem trajectories of Iowa gambling treatment program participants. J Gambl Stud. 2006; 22:221-240. [PubMed: 16838101]

37. Winters KC, Stinchfield RD, Botzet A, et al. A prospective study of youth gambling behaviors. Psychol Addict Behav. 2002; 16:3-9. [PubMed: 11934084]

38. Jessor, R.; Jessor, SL. Problem behavior and psychosocial development: A longitudinal study of youth. Academic Press; New York: 1977. 
Table 1

Frequency Distributions for Demographic Characteristics $(\mathrm{n}=515)$

\begin{tabular}{|c|c|c|}
\hline Demographic Characteristic & & Frequency (Valid \%) \\
\hline \multirow[t]{3}{*}{ Gender } & Male & $283(55.0)$ \\
\hline & Female & $232(45.0)$ \\
\hline & Missing & 0 \\
\hline \multirow[t]{4}{*}{ Birth Year } & 1986 & $31(6.0)$ \\
\hline & 1987 & $483(93.8)$ \\
\hline & 1988 & $1(0.2)$ \\
\hline & Missing & 0 \\
\hline \multirow[t]{3}{*}{ Race } & Black & $452(87.8)$ \\
\hline & White & $63(12.2)$ \\
\hline & Missing & 0 \\
\hline \multirow[t]{3}{*}{ Lunch Status (in 1993 at age 7, entry into $1^{\text {st }}$ grade) } & Paid & $153(30.0)$ \\
\hline & Free or Reduced & $357(70.0)$ \\
\hline & Missing & 5 \\
\hline \multirow[t]{4}{*}{ Intervention Status (in 1993 at age 7 , entry into $1^{\text {st }}$ grade) } & Control & $169(32.8)$ \\
\hline & Classroom & $167(32.4)$ \\
\hline & Family & $179(34.8)$ \\
\hline & Missing & 0 \\
\hline \multirow[t]{3}{*}{ Conduct Disorder (in 2004 , at age 17 , typically $11^{\text {th }}$ grade) } & No & $492(95.5)$ \\
\hline & Yes & $23(4.5)$ \\
\hline & Missing & 0 \\
\hline \multirow[t]{2}{*}{ Parental Monitoring (in 2004, at age 17 , typically $11^{\text {th }}$ grade) } & Mean $=2.29(S D=.91)$ & \\
\hline & Median $=2.14$ & \\
\hline \multirow[t]{2}{*}{ Neighborhood Environment (in 2004 , at age 17, typically $11^{\text {th }}$ grade) } & Mean $=1.74(S D=.63)$ & \\
\hline & Median $=1.60$ & \\
\hline
\end{tabular}



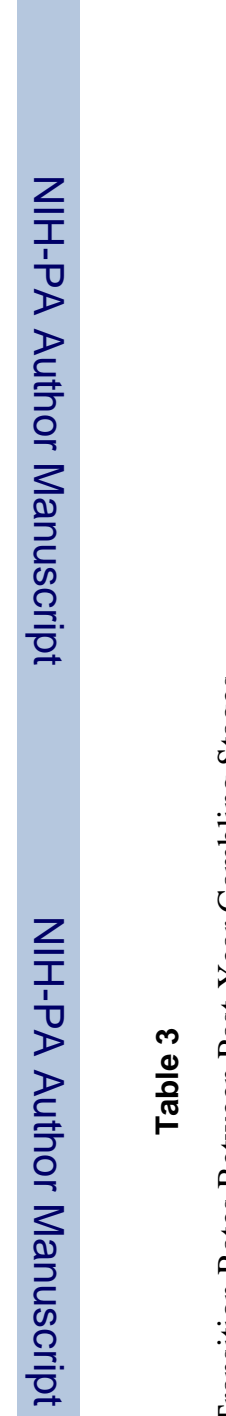

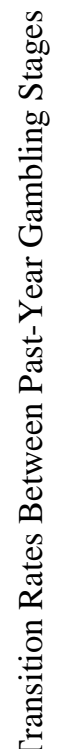

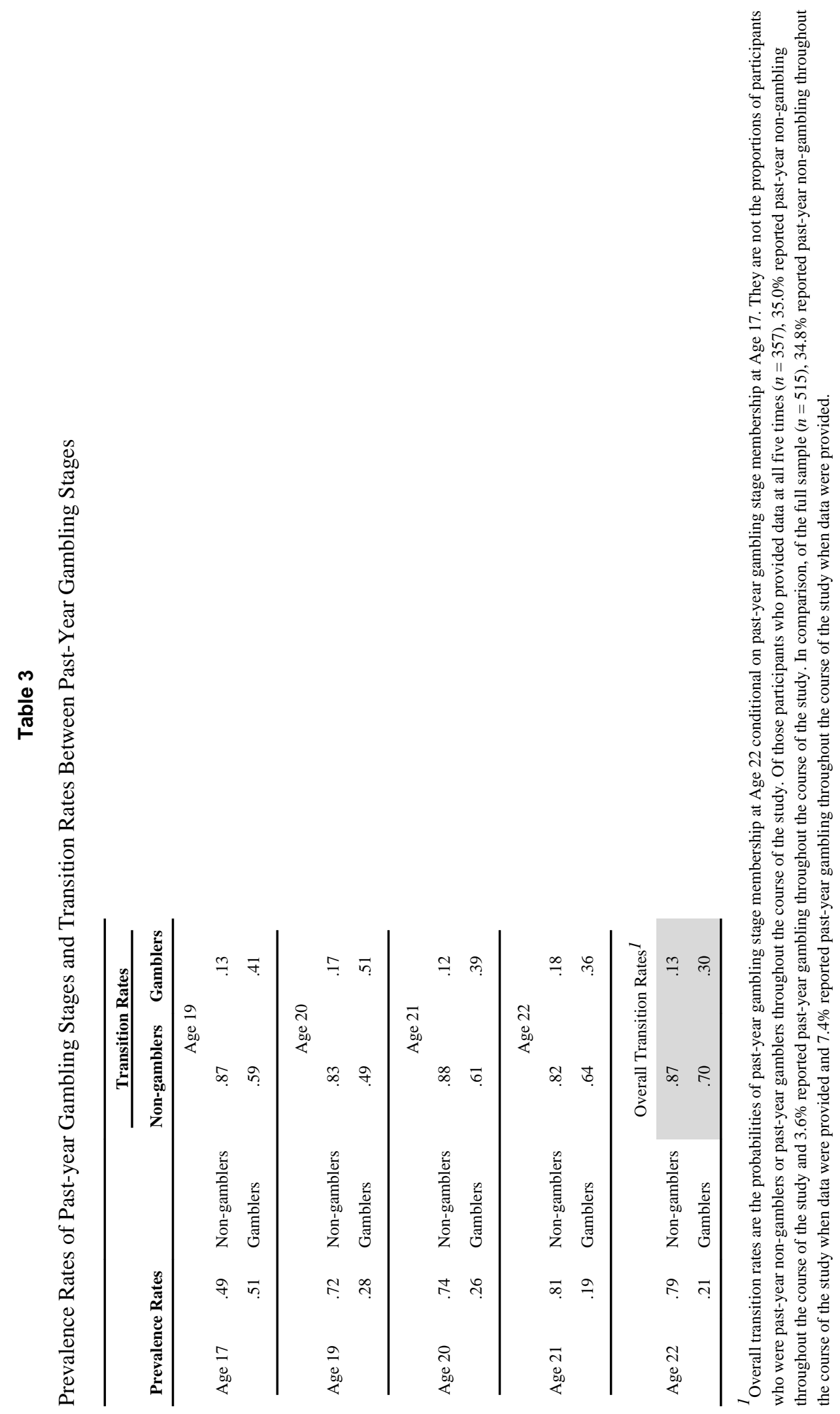




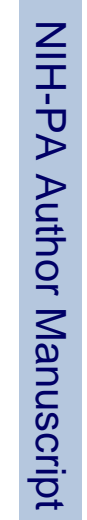
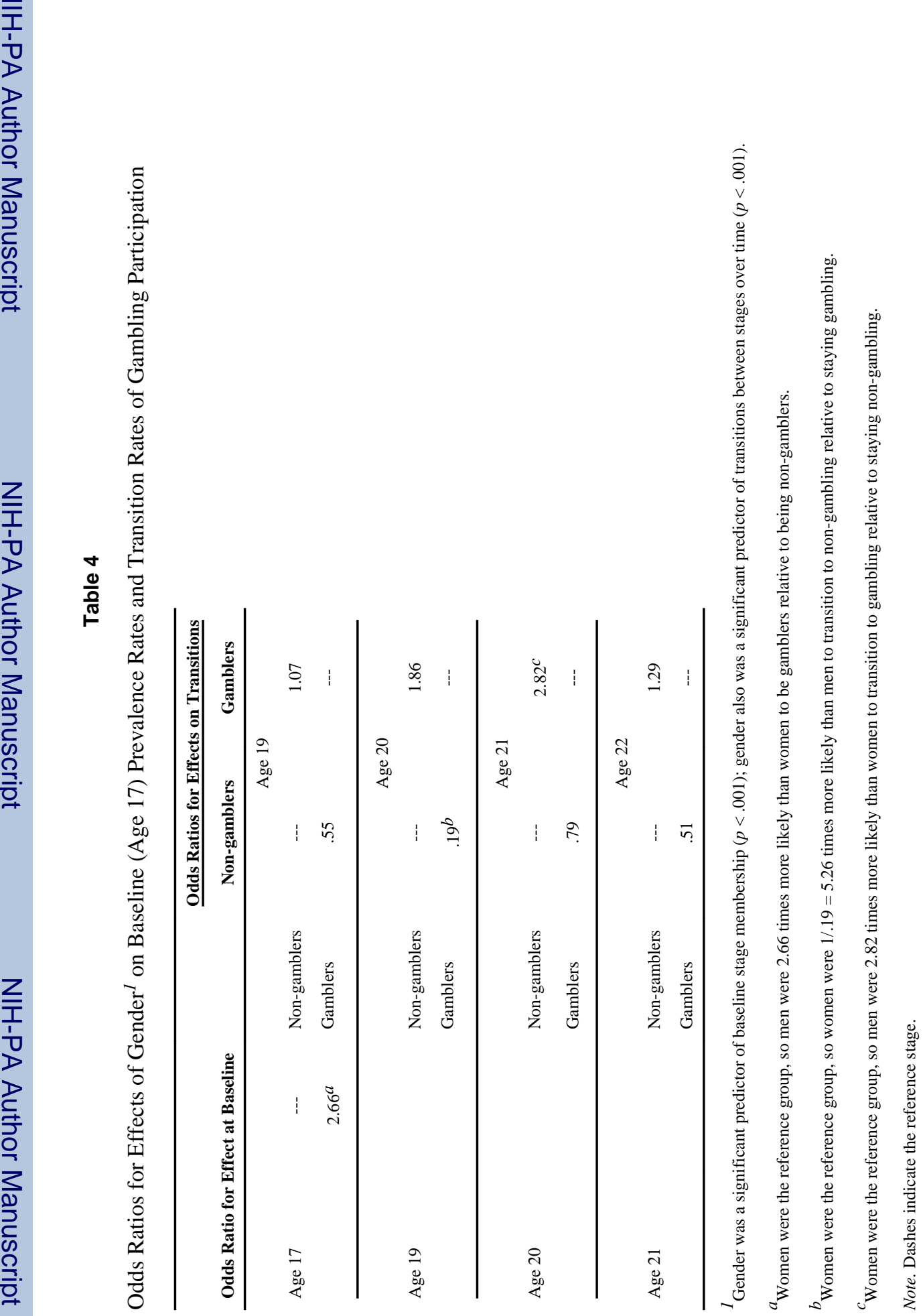

J Adolesc Health. Author manuscript; available in PMC 2015 August 01. 


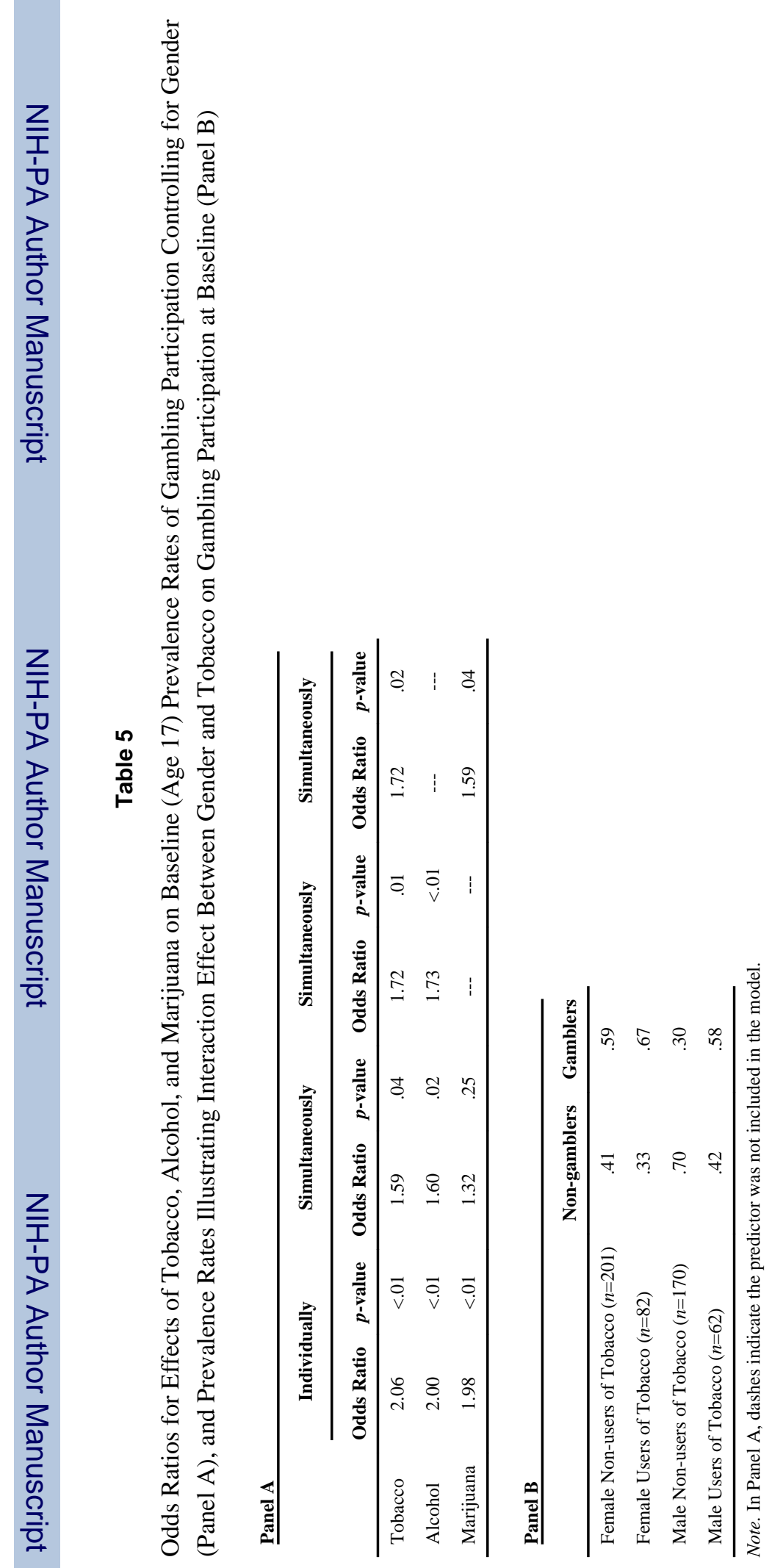

